\title{
PRECISE CALENDRICAL DATING OF KNOWN GROWTH-PERIOD SAMPLES USING A 'CURVE FITTING' TECHNIQUE
}

\author{
G W PEARSON \\ Palaeoecology Centre, The Queen's University of Belfast \\ Northern Ireland
}

\begin{abstract}
Absolute high-precision radiocarbon time-scale calibration is now available and is shown by Stuiver and Pearson (1986) and Pearson and Stuiver (1986) to be internationally valid. The technique of curve fitting presented in this paper shows how certain samples may be dated calendrically to within a very narrow band width ca \pm 20 years, at time periods when single sample analysis would give ambiguous calendrical conversion. Samples of known deposition rate covering a time span of $>50$ years are subdivided to produce a 'floating curve' and this curve is then 'wiggle matched' with the high-precision calibration to give a precise calendrical age.
\end{abstract}

\section{INTRODUCTION}

The short-term variation in atmospheric ${ }^{14} \mathrm{C}$ concentration can be used to achieve precise calendrical ages for certain types of samples where the growth period is known and is in excess of 50 years. Wood is the best example of a desirable type, having a defined growth rate as indicated by the annual rings, and quite often covering more than 100 years.

While some wood samples can be precisely dated dendrochronologically, the method is limited to particular wood species, to samples having $>100$ annual growth rings, and to the availability of an appropriate master chronology. This curve fitting or 'wiggle matching' technique can theoretically be used for any type of sample and need not necessarily be limited to wood; any defined growth-period sample would suffice including samples which have a 'known' deposition rate, eg, peat.

The sample selected for demonstration of this technique was a piece of wood from an archaeologic excavation that contained ca 150 annual growth rings which could not be dated dendrochronologically. Five discrete contiguous samples of 20-year growth periods (as per high-precision ${ }^{14} \mathrm{C}$ time-scale calibration) (Pearson et al, 1986) were taken from the sample. The center of the youngest bi-decade corresponded to Tree-ring 138. It should be noted that no sap-wood was present and an allowance would have to be made for its loss, in the final calendrical estimate.

The five samples were prepared, the ${ }^{14} \mathrm{C}$ measured, and the date calculated as for calibration samples (Pearson, 1979) so as to be directly comparable with the individual sample ${ }^{14} \mathrm{C}$ dates of the high-precision calibration. The ${ }^{14} \mathrm{C}$ dates were plotted against annual growth rings to form a minifloating curve covering a $0-100$ year period similar in form to the composition of the calibration curve. This 'floating' curve should exhibit the same variations as the calibration curve at the same time period (within statistical expectations) (see Fig 1A).

\section{METHOD}

The individual ${ }^{14} \mathrm{C}$ dates of the 5 samples of the floating curve $\mathrm{x}_{1}, \mathrm{x}_{2} \ldots$ $\mathrm{x}_{5}$ were compared with corresponding interval ${ }^{14} \mathrm{C}$ dates of the high-preci- 


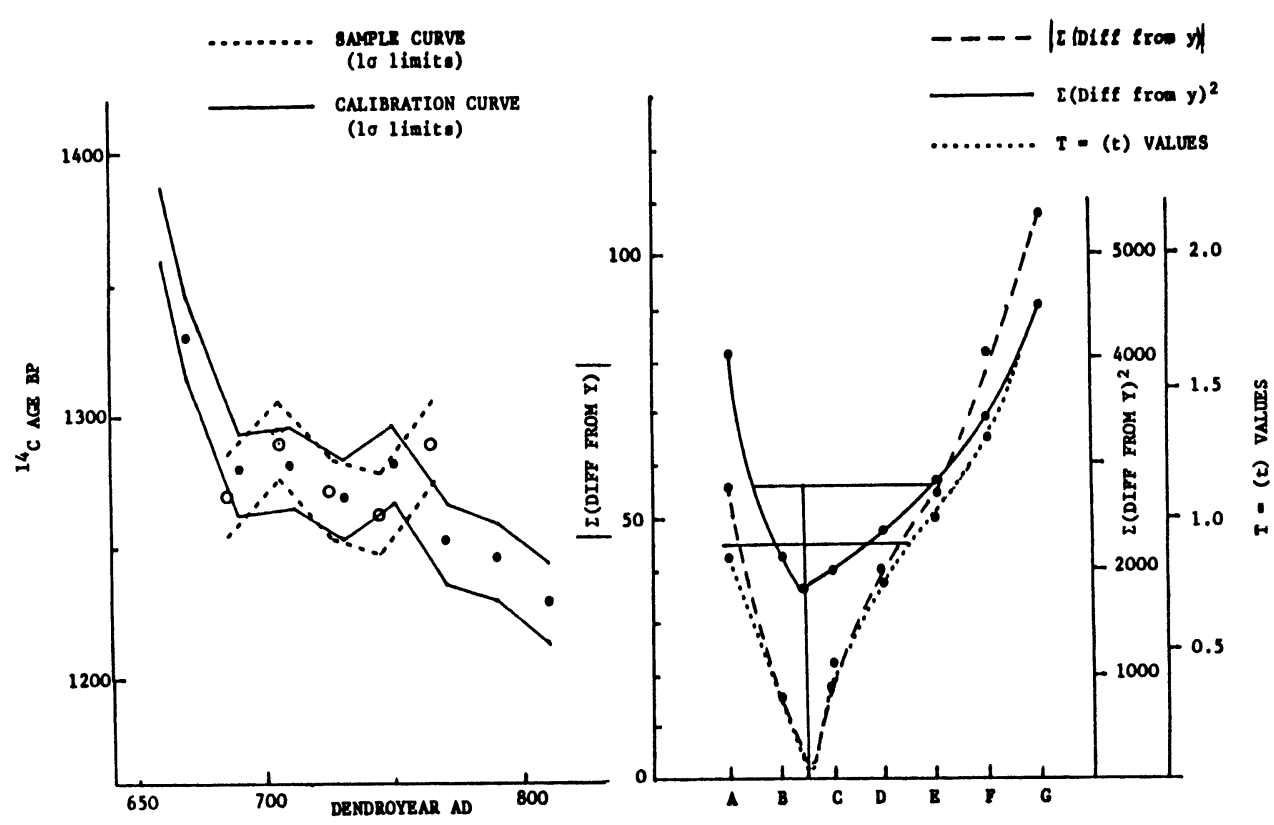

Fig 1A. The best fit of the sample data (dotted lines) with the calibration curve. Standard deviations of $1 \sigma= \pm 15 \mathrm{yr}$ are plotted. $N B$. Since this analysis was performed, duplicate measurement of AD 730 has slightly changed its value giving a slight movement in point of match.

Fig 1B. The curves of the various statistical tests at the positions tested. The curves reach a minimum at the proposed point of match. The confidence intervals used are shown as horizontal lines across the (SS) and the (' $t$ ') statistic curves. The confidence interval can be determined by the projection of these limits onto the $x$ axis where $A-B$. . G are equivalent to 10 years each.

sion calibration at position $t_{1}, t_{2} \ldots t_{5}$ (Point A, Table 1 ) where $t_{1}, t_{2} \ldots t_{5}$ are the calendrical ages corresponding to the ${ }^{14} \mathrm{C}$ dates $\mathrm{y}_{1}, \mathrm{y}_{2} \ldots \mathrm{y}_{5}$ (calibration curve ${ }^{14} \mathrm{C}$ date values). The sum of the differences $\mathrm{SD}=\left(\mathrm{x}_{1}-\mathrm{y}_{1}\right)+$ $\left(x_{2}-y_{2}\right) \ldots+\left(x_{5}-y_{5}\right)$, and the sum of the (differences) $)^{2} S S=\left(x_{1}-y_{1}\right)^{2}+$ $\left(\mathrm{x}_{2}-\mathrm{y}_{2}\right)^{2} \ldots+\left(\mathrm{x}_{5}-\mathrm{y}_{5}\right)^{2}$ were then calculated. The 'floating' curve ${ }^{14} \mathrm{C}$ dates were then moved 10 calendar years and compared with the interpolated ${ }^{14} \mathrm{C}$ dates from the calibration and the SD and SS again calculated. Point $\mathrm{B}$, Table 1 is the position now occupied by the floating curve corresponding to $\left(t_{1}+10\right),\left(t_{2}+10\right) \ldots\left(t_{5}+10\right)$ calendrical ages. This process was repeated to cover the whole of the selected range A-G (Table 1) comparing floating curve ${ }^{14} \mathrm{C}$ dates with calibration curve ${ }^{14} \mathrm{C}$ dates at each 10 calendar year movement (interpolated calibration curve ${ }^{14} \mathrm{C}$ dates had to be evaluated and used for alternate moves since the calibration curve interval is normally $20 \mathrm{yr}$ ). In addition to the above calculations the balance of individual differences in each position was considered in light of statistical expectation, such as the probability of all differences being either negative or positive, or any single measurement for each position exceeding $2\left\{\left(\sigma_{1}\right)^{2}+\left(\sigma_{2}\right)^{2}\right\}^{1 / 2}$ where $\sigma_{1}$ and $\sigma_{2}$ are the standard deviations of the individual ${ }^{14} \mathrm{C}$ dates of the floating curve and calibration curve, respectively. Such 


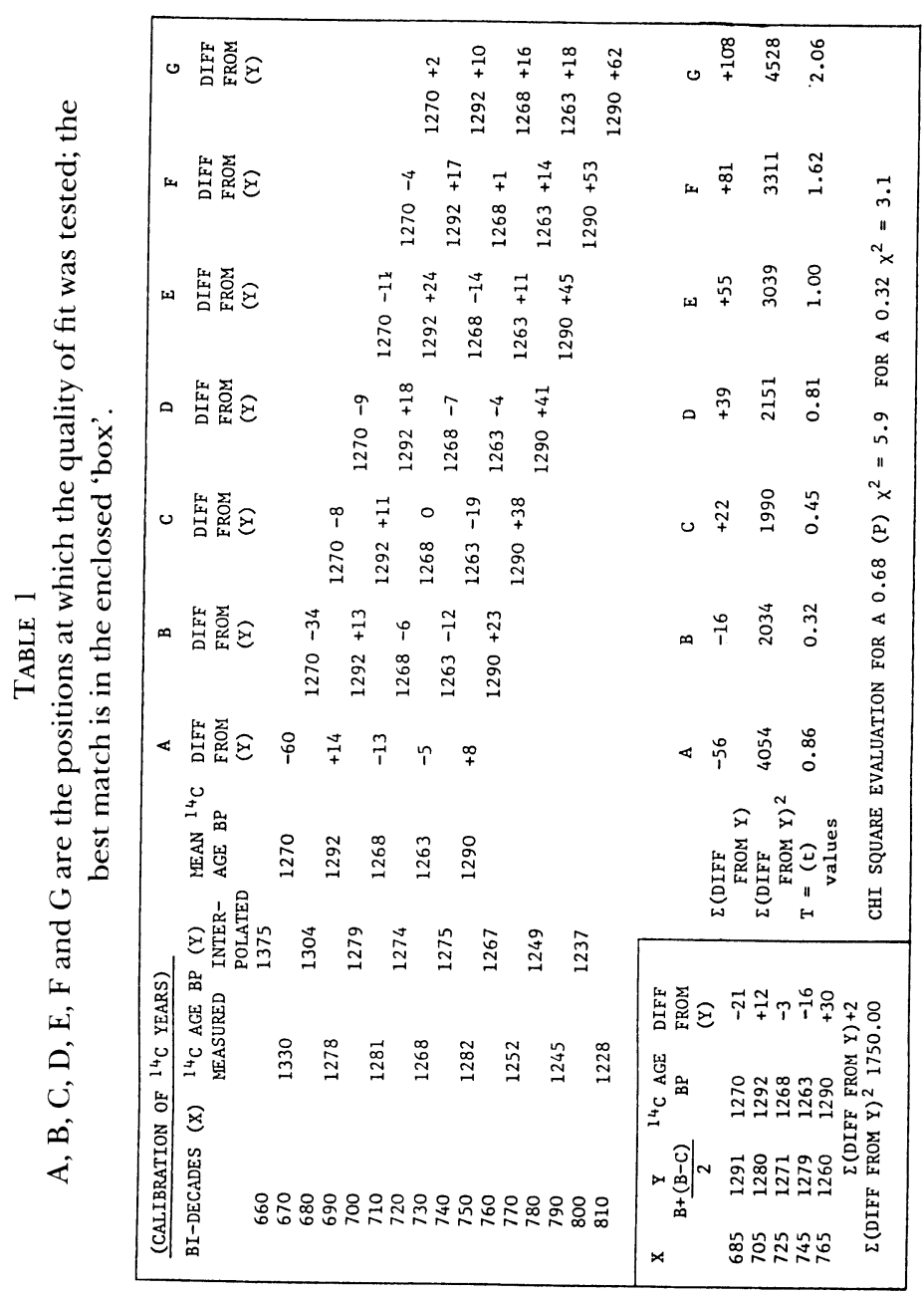


criteria are readily observed in Table 1 which gives the detailed sample analysis used for the calendrical dating of the selected sample.

\section{THEORY}

From the above, if $\mathrm{x}_{1}, \mathrm{x}_{2} \ldots \mathrm{x}_{5}$ are the ${ }^{14} \mathrm{C}$ dates of the floating curve and $\mathrm{y}_{1}, \mathrm{y}_{2} \ldots \mathrm{y}_{5}$ are the corresponding ${ }^{14} \mathrm{C}$ dates from which the high-precision calibration curve was constructed (Fig 1) (interpolated where required), then $\left(x_{1}-y_{1}\right)+\left(x_{2}-y_{2}\right) \ldots+\left(x_{5}-y_{5}\right)$ and $\left(x_{1}-y_{1}\right)^{2}+$ $\left(x_{2}-y_{2}\right)^{2} \ldots\left(x_{5}-y_{5}\right)^{2}$ will give a minimum at the point of match. The relationship of this least square value to the standard deviation of both curves is set out below.

Let $x_{i}$ and $y_{i}$ represent the above individual ${ }^{14} \mathrm{C}$ dates from the floating curve and the calibration curve, respectively, where $\mathrm{i}=1 \rightarrow \mathrm{n}$ (in this case $\mathrm{n}=5$ ). Let $\mu_{\mathrm{i}}=$ mean of each data pair, $i e$,

$$
\mu_{1}=\frac{\mathrm{x}_{1}+\mathrm{y}_{1}}{2}, \mu_{2}=\frac{\mathrm{x}_{2}+\mathrm{y}_{2}}{2}, \ldots \mu_{\mathrm{n}}=\frac{\mathrm{x}_{\mathrm{n}}+\mathrm{y}_{\mathrm{n}}}{2} .
$$

At the point of match the values of $\mu$ for each data pair can be assumed to be the best approximation of the true ${ }^{14} \mathrm{C}$ date since they can be considered to be duplicate analyses. Then

$$
\begin{aligned}
& \text { the sum of the (differences) })^{2}=\mathrm{SS}=\sum_{\mathrm{i}=1}^{\mathrm{n}}\left(\mathrm{x}_{\mathrm{i}}-\mathrm{y}_{\mathrm{i}}\right)^{2} \\
& \text { or } \mathrm{SS}=\sum_{\mathrm{i}=1}^{\mathrm{n}}\left\{\left(\mathrm{x}_{\mathrm{i}}-\mu_{\mathrm{i}}\right)-\left(\mathrm{y}_{\mathrm{i}}-\mu_{\mathrm{i}}\right)\right\}^{2} \\
& \text { or } \mathrm{SS}=\sum_{\mathrm{i}=1}^{\mathrm{n}}-2\left(\mathrm{x}_{\mathrm{i}}-\mu_{\mathrm{i}}\right)\left(\mathrm{y}_{\mathrm{i}}-\mu_{\mathrm{i}}\right)+\left(\mathrm{x}_{\mathrm{i}}-\mu_{\mathrm{i}}\right)^{2}+\left(\mathrm{y}_{\mathrm{i}}-\mu_{\mathrm{i}}\right)^{2} .
\end{aligned}
$$

Let $\epsilon$ be designated as the expected value.

$$
\text { The } \epsilon S S=\sum_{\mathrm{i}=1}^{\mathrm{n}}-2 \epsilon\left(\mathrm{x}_{\mathrm{i}}-\mu_{\mathrm{i}}\right)\left(\mathrm{y}_{\mathrm{i}}-\mu_{\mathrm{i}}\right)+\epsilon\left(\mathrm{x}_{\mathrm{i}}-\mu_{\mathrm{i}}\right)^{2}+\epsilon\left(\mathrm{y}_{\mathrm{i}}-\mu_{\mathrm{i}}\right)^{2}
$$

It can be assumed that

$$
\sum_{\mathrm{i}=1}^{\mathrm{n}} \epsilon\left(\mathrm{x}_{\mathrm{i}}-\mathrm{y}_{\mathrm{i}}\right)=0
$$

at the point of match, and it follows that

$$
\sum_{\mathrm{i}=1}^{\mathrm{n}} \epsilon\left(\mathrm{x}_{\mathrm{i}}-\mu_{\mathrm{i}}\right)=\sum_{\mathrm{i}=1}^{\mathrm{n}} \epsilon\left(\mathrm{y}_{\mathrm{i}}-\mu_{\mathrm{i}}\right)=0 .
$$

Thus, Equation (1) can be rewritten as

$$
\epsilon \mathrm{SS}=\sum_{\mathrm{i}=1}^{\mathrm{n}} \epsilon\left(\mathrm{x}_{\mathrm{i}}-\mu_{\mathrm{i}}\right)^{2}+\epsilon\left(\mathrm{y}_{\mathrm{i}}-\mu_{\mathrm{i}}\right)^{2}
$$

But $\left(\mathrm{x}_{\mathrm{i}}-\mu_{\mathrm{i}}\right)^{2}$ and $\left(\mathrm{y}_{\mathrm{i}}-\mu_{\mathrm{i}}\right)^{2}=\sigma \mathrm{x}_{\mathrm{i}}^{2}$ and $\sigma \mathrm{y}_{\mathrm{i}}^{2}$, respectively, $\therefore \epsilon \mathrm{SS}=\mathrm{n}\left(\sigma_{\mathrm{x}}^{2}+\sigma_{\mathrm{y}}^{2}\right)$ if 
$\sigma \mathrm{x}_{\mathrm{i}}$ are all the same and $\sigma \mathrm{y}_{\mathrm{i}}$ are all the same and

$$
\mathrm{SS}=2 \mathrm{n} \sigma^{2} \text { if } \sigma_{\mathrm{x}_{\mathrm{i}}}=\sigma_{\mathrm{y}_{\mathrm{i}}} .
$$

From (2) the expected standard deviation $\hat{\sigma}$ could also be evaluated from the measured (SS) value of $\mathrm{n}$ paired data sets $(\hat{\sigma}=$ expected standard deviation) where

$$
\hat{\sigma}^{2}=\frac{\mathrm{SS}}{2 \mathrm{n}} \text { if } \sigma \mathrm{x}=\sigma \mathrm{y}
$$

or

$$
\sigma_{\mathrm{x}}^{2}+\sigma_{\mathrm{y}}^{2}=\frac{\mathrm{SS}}{\mathrm{n}} \text { if } \sigma \mathrm{x} \neq \sigma \mathrm{y} .
$$

As stated above the sum of the differences between the individually paired ${ }^{14} \mathrm{C}$ dates should be zero at the point of match, assuming no significant off-set between the floating and calibration curves. It was therefore considered worth plotting this parameter as confirmation of the minimum square curve. The minimum of the two curves (SD) and (SS) need not necessarily coincide.

From the above evaluation of expected values it should be possible to conclude the quality of fit of any floating curve to the calibration curve and hence obtain a reliable calendrical age for the sample under analysis. If in addition to the plotting of the SD and SS a paired ' $t$ ' statistic is evaluated and plotted, a more accurate position of the match can be obtained.

\section{CONFIDENCE INTERVAL}

The confidence interval for $\hat{\sigma}^{2}$ (where $\hat{\sigma}^{2}$ is an estimate of $\sigma^{2}$ and from above is equal to SS/2n) can be estimated if it is assumed that $x_{i}$ and $y_{i}$ are normally distributed.

We assume that $x_{i}$ and $y_{i}$ are distributed as a normal distribution (N) with mean $\left(\mu_{\mathrm{i}}\right)$ and variance $\left(\sigma^{2}\right)$.

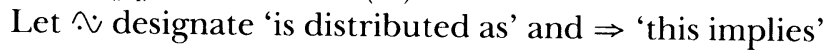

$$
\begin{aligned}
& \mathrm{x}_{\mathrm{i}} \curvearrowright \mathrm{N}\left(\mu_{\mathrm{i}}, \sigma^{2}\right) \text { and } \mathrm{y}_{\mathrm{i}} \curvearrowright \mathrm{N}\left(\mu_{\mathrm{i}}, \sigma^{2}\right)
\end{aligned}
$$

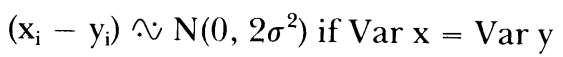

$$
\begin{aligned}
& \frac{\left(\mathrm{x}_{\mathrm{i}}-\mathrm{y}_{\mathrm{i}}\right)}{\sqrt{2} \sigma} \curvearrowright \mathrm{N}(0,1)
\end{aligned}
$$

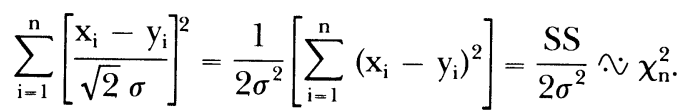

Hence, if the probability of

then the probability of

$$
\left[\operatorname{lower}(\ell)_{\chi_{n}^{2}}<\frac{S S}{2 \sigma^{2}}<\operatorname{upper}(\mathrm{u})_{\chi_{n}^{2}}\right]=\mathrm{P}
$$

$$
\left[\frac{2 \ell_{\chi_{n}^{2}}}{\mathrm{SS}}<\frac{1}{\sigma^{2}}<\frac{2 \mathrm{u}_{\chi_{n}^{2}}}{\mathrm{SS}}\right]=\mathrm{P}
$$


but expected (SS) $=2 \mathrm{n} \sigma^{2}$. Hence, if the confidence interval for $\sigma^{2}$ from above is

$$
\frac{\mathrm{SS}}{2 \mathrm{l}_{\chi_{\mathrm{n}}^{2}}}<\sigma^{2}<\frac{\mathrm{SS}}{2 \mathrm{u}_{\chi_{n}^{2}}}
$$

then the confidence interval for $2 \mathrm{n} \sigma^{2}$ is

$$
\frac{\mathrm{n}(\mathrm{SS})}{\ell_{x_{\mathrm{n}}^{2}}}<2 \mathrm{n} \sigma^{2}<\frac{\mathrm{n}(\mathrm{SS})}{\mathrm{u}_{x_{\mathrm{n}}^{2}}}
$$

for $\mathrm{n}=5$ and $\mathrm{P}=0.68\left(i e, 1 \sigma\right.$ level) from $\chi^{2}$ tables we get

$$
\begin{gathered}
\ell_{\chi_{5}^{2}}=5.9 \text { and } \mu_{\chi_{5}^{2}}=3.1 \\
\text { confidence limits }=\frac{\mathrm{n}(\mathrm{SS})}{5.9}=0.85(\mathrm{SS}) \text { and } \frac{\mathrm{n}(\mathrm{SS})}{3.1}=1.61(\mathrm{SS}) \text {. }
\end{gathered}
$$

\section{RESULT}

From the above statement and illustrated in Figure 1B, the estimated confidence limits are

$$
\begin{aligned}
& \text { Lower limit } 0.85(\mathrm{SS})=0.85(1750)=1487 \\
& \text { Upper limit } 1.61(\mathrm{SS})=1.61(1750)=2817 .
\end{aligned}
$$

All (SS) results falling between 1487 and 2817 are valid matches within the probabilities chosen. This gives a calendar range of 32 years (Fig 1B), ie, it is probable $(0.68)$ that Ring 138 lies between $755-787$ calendar years $\mathrm{BC}$, $i e$, a 32-year range (only the upper limit of 2817 is used for maximum range error).

The standard deviation calculated from the (SS) minimum at 1750 is less than that quoted on individual measurements, $13.2 \mathrm{yr}$ to $15 \mathrm{yr}$, respectively, but this may be expected from so few samples.

The sum of the differences is close to zero which is the theoretical minimum. A paired ' $t$ ' statistic was evaluated using

$$
\left.\begin{array}{l}
x_{1} x_{2} \ldots x_{n} \\
y_{1} y_{2} \ldots y_{n}
\end{array}\right\} \begin{aligned}
& \text { as paired observation from a normal distribution } \\
& \text { having means of } \mu_{x}, \mu_{y}
\end{aligned}
$$

if $\mathrm{i}=1 \rightarrow \mathrm{n}$ then

$$
\begin{aligned}
& D i=x_{i}-y_{i} \\
& \bar{D}=\frac{1}{n} \sum_{i=1}^{n} D_{i} \\
& \sigma=\sqrt{\frac{\sum D_{i}^{2}-\frac{1}{n}\left(\sum D_{i}\right)^{2}}{n-1}}
\end{aligned}
$$


(Ostle, 1963). The test statistic

$$
\mathrm{t}=\frac{\overline{\mathrm{D}}}{\sigma} \cdot \sqrt{\mathrm{n}}
$$

The ' $\mathrm{t}$ ' value Table 1 was used to test the Null hypothesis Ho: $\mu_{\mathrm{x}}=\mu_{\mathrm{y}}$, $i e$, that both means are equal.

At the point of match, $i e$, between B and C, Fig $1 \mathrm{~B}, \mathrm{t}=0.04$ with 4 degrees of freedom indicating no difference in the mean at better than $90 \%$ probability. At \pm 5 years from the point of match ' $t$ ' values were 0.45 and 0.32 , respectively, giving a $70-80 \%$ probability, and at \pm 15 year divergence the probability of having similar means was $<50 \%$ calculated from ' $t$ ' values $>0.8$.

In consideration of the above analysis it is not statistically valid to pinpoint the match as the visual presentation would imply. Both the (SS) values and ' $t$ ' statistic indicate a confidence interval within which the match could lie and both cover almost the same time interval of ca 30 years. It is concluded that the visual match, $i e$, the coincident minimum of the three mathematical determinations is the most likely estimate of the position of match, but the confidence interval is taken as that derived from the (SS) analysis and is also supported by the ' $t$ ' statistical test.

Thus, the best match is considered to be

$$
\begin{aligned}
& \text { Ring } 138 \equiv \mathrm{AD} 765_{-10}^{+22} \text { years } \\
& \text { Ring } 150 \equiv \mathrm{AD} 777_{-10}^{+22}
\end{aligned}
$$

This gives a felling date after making an allowance for the loss of sap-wood, $i e, 32 \pm 9$ years of

felling date $=\mathrm{AD} 809_{-13}^{+24}$; the limits of confidence are at the $1 \sigma$ level.

\section{CONCLUSION}

Pearson et al (1986) indicate that the fine detail of the natural variation of ${ }^{14} \mathrm{C}$ concentration in the atmosphere is likely to be of considerable interest to workers in many disciplines, but perhaps its greatest significance is in the field of archaeology. Much greater resolution is now available for solving many chronologic problems and the curve fitting technique discussed in this paper adds another valuable tool for use at time periods when the calibration curve would significantly increase the calendrically converted band width beyond the precision of the ${ }^{14} \mathrm{C}$ date. The high-precision curve is essential for converting high-precision analysis and it has already proved useful in solving some archaeologic dating problems from the late Bronze age/early Iron age where the calibration curve is almost horizontal from $400->700$ BC. Samples dated ca $2450 \mathrm{BP}$, eg, with precisions of ca $\pm 100 \mathrm{yr}$ could not be converted to a calendar age band with any greater resolution than $480 \mathrm{yr}(750-270 \mathrm{BC})$. Using high-precision measurement ca $\pm 20 \mathrm{yr}$, this band width for the above example can be reduced to almost 10 years. Single high-precision analysis of samples can give calendrical band widths similar to the ${ }^{14} \mathrm{C}$ quoted error range over considerable portions of the calibration and a combination of this with the curve fitting technique will allow 
narrow calendrical age bands to be determined for $>90 \%$ of the time period covered by the high-precision calibration curve.

The above curve fitting analysis is limited to samples with a fairly long growth period and are of known deposition or growth rate, such that subdivision of the sample is possible into a number of discrete contiguous samples of approximately the same growth period as the calibration curve. The number of sub-samples required depends to some extent on the position of the match (one sample is all that is required for large portions of the curve) but the time period covered by the sample rarely needs to exceed 100 years. A number of archaeologic samples have now been analyzed by this technique and Pearson and Baillie (ms in preparation) will describe some of the results and implications for archaeology.

In conclusion, high-precision analysis can provide fine calendrical resolution to the archaeologic chronology, providing, of course, the samples are submitted with adequate information, such as precise association and provenience to allow for correct interpretation (see Kra, 1986).

$N B$ : This research forms part of a PhD thesis by the author (Pearson, 1983 ) and is now available for consultation if more detail is required.

\section{ACKNOWLEDGMENTS}

The author would like to thank F Qua and E Glass who were responsible for the routine analysis of these samples and M G L Baillie who provided them. Thanks are also extended to D Chambers, Applied Math and Theoretical Physics department of QUB for his assistance in the statistical analysis. Thanks are also given to S E R C for a grant for this research.

\section{REFERENCES}

Kra, R S, 1986, Standardizing procedures for collecting, submitting, recording, and reporting of radiocarbon samples, in Stuiver, $\mathrm{M}$ and $\mathrm{Kra}, \mathrm{R} S$, eds, Internatl ${ }^{14} \mathrm{C}$ conf, 12 th, Proc: Radiocarbon, this issue.

Ostle, B, 1963, Statistics in research: Iowa State Univ Press.

Pearson, G W, 1979, Precise ${ }^{14} \mathrm{C}$ measurement by liquid scintillation counting: Radiocarbon, $v$ $21, \mathrm{p} 1-21$.

- (ms), 1983, The development of high precision ${ }^{14} \mathrm{C}$ measurement and its application to archaeological time-scale problems: PhD dissert, The Queen's Univ Belfast.

Pearson, G W. Pilcher, J R, Baillie, M G, Corbett, D M and Qua, F, 1986, High-precision ${ }^{14} \mathrm{C}$ measurement of Irish oaks to show the natural variations from AD 1840 to $5210 \mathrm{BC}$, in Stuiver, $\mathrm{M}$ and Kra, R S, eds, Internatl ${ }^{14} \mathrm{C}$ conf, 12th, Proc: Radiocarbon, v 28, no. $2 \mathrm{~B}$.

Pearson, G W and Stuiver, M, 1986, High-precision radiocarbon time-scale calibration from $500 \mathrm{BC}$ to $2500 \mathrm{BC}$, in Stuiver, $\mathrm{M}$ and Kra, R S, eds, Internatl ${ }^{14} \mathrm{C}$ conf, 12 th, Proc: Radiocarbon, $\mathrm{v} 28$, no. $2 \mathrm{~B}$.

Stuiver, $\mathrm{M}$ and Pearson, G W, 1986, High-precision radiocarbon time-scale calibration from the present to $500 \mathrm{BC}$, in Stuiver, $\mathrm{M}$ and Kra, R S, eds, Internatl ${ }^{14} \mathrm{C}$ conf, 12 th, Proc: Radiocarbon, v 28, no. $2 \mathrm{~B}$. 